\title{
Research involving storage and use of human tissue: how did the Human Tissue Act 2004 affect decisions by Research Ethics Committees?
}

Emma Angell, Research Associate, Social Sciences Research Group, Department of Health Sciences, University of Leicester, Leicester LE1 7RH, tel: +44 (0)116 229 7256, fax: +44 (0)116 229 7250, email: el1@le.ac.uk [CORRESPONDING AUTHOR]

Carolyn Tarrant, Lecturer in Health Psychology, Social Sciences Research Group, Department of Health Sciences, University of Leicester, Leicester LE1 7RH, ccp3@le.ac.uk

Mary Dixon-Woods, Professor of Medical Sociology, Social Sciences Research Group, Department of Health Sciences, University of Leicester, Leicester LE1 7RH, md11@le.ac.uk

Keywords: medical law; human tissue act; research ethics committees; human tissue

Word count of main text: 3712 (excluding tables)

The Corresponding Author has the right to grant on behalf of all authors and does grant on behalf of all authors, an exclusive licence (or non-exclusive for government employees) on a worldwide basis to the BMJ Publishing Group Ltd and its Licensees to permit this article (if accepted) to be published in JCP and any other BMJPGL products to exploit all subsidiary rights, as set out in our licence. 


\section{ABSTRACT}

\section{Aims}

Little is known about the types of issues Research Ethics Committees (RECs) raise in their letters about research involving the storage and use of human tissue. We sought to classify the issues that appear to trouble RECs and to identify how the implementation of the Human Tissue (HT) Act in September 2006 might have affected REC decisions.

\section{Methods}

100 letters relating to applications about research use of human tissue were randomly selected from the National Research Ethics Service database, of which half were issued before the implementation of the HT Act and half post implementation. Ethical issues raised by RECs were classified with a coding scheme developed using Ethnographic Content Analysis.

\section{Results}

Many letters raised issues about informed consent, including specific concerns about the information to be provided to participants about the taking, using and storing of their tissue samples. However, RECs appeared to be less likely to raise concerns about informed consent to use or store tissue after the HT Act, and there was some evidence that RECs were more comfortable allowing archived tissue samples to be used without additional patient consent after the HT Act than before.

\section{Conclusions}

In the wake of the HT Act, RECs do not appear to be more cautious about approving research to use or store tissue without consent when responding to applications for ethical approval. The HT Act has provided clarity and authority to RECs and may indeed facilitate the process of gaining ethical approval for tissue-based research.

Abstract word count: 246 


\section{INTRODUCTION}

The introduction of the Human Tissue (HT) Act 2004, ${ }^{1}$ which was implemented in September 2006 in the UK, can be understood as a response to concerns raised by events at Bristol Royal Infirmary and the Royal Liverpool Children's Hospital, where organs and tissue from children who had died were removed and stored without proper consent. ${ }^{2,3}$ The HT Act now regulates the storage, use and disposal of human tissue in England, Wales and Northern Ireland. The Act does not regulate the taking or removal of tissue from living people for research, which remains governed by common law. Broadly, if researchers plan to use 'surplus' material 'left over' after biopsies, operations or other procedures, then no separate consent to the procedure to take the tissue, over and above the normal consent to treatment, is required. But if additional procedures are to be undertaken to obtain material specifically for research (e.g. extra biopsies), the patient must give separate consent for this. ${ }^{4}$ The HT Act does require researchers to obtain consent for the storage and use of tissue for research purposes, though it also allows the storage and use of human tissue from the living without consent provided that the research is ethically approved and the tissue is anonymised. ${ }^{5}$ Stored or 'archived' tissue may also be used without consent following considerations about whether other sources of tissue are available, the feasibility of tracing and contacting donors, and the potential for the research to discover information of clinical significance for donors or to cause them unnecessary further distress. ${ }^{4}$

The new legislation gives Research Ethics Committees (RECs) important roles in the governance of research involving human tissue, requiring RECs to make judgements about the appropriateness of consent arrangements. RECs can approve applications to conduct studies where researchers aim to access tissue without consent in cases where obtaining consent may be impractical or may cause distress, but they can also choose to insist that consent be obtained if they deem it appropriate. The fear that RECs might show undue caution in making decisions about research involving human tissue, obstructing the conduct of potentially low risk and high value research, has been expressed by the Royal College of Pathologists, ${ }^{6}$ amongst others. There is also concern that aspects of the Human Tissue Authority's (HTA) Codes of Practice might be problematic for RECs to interpret, including the lack of direct legislation about whether consent should be generic or specific. ${ }^{7}$

Despite the concerns that the implementation of the Human Tissue Act could hamper important medical research, ${ }^{6}$ little is known about the impact of the Act on the work of Research Ethics Committees. The aim of this paper is to identify the ethical issues raised by RECs in the letters about use of human tissue for research purposes, and to offer some insights the impact of the HT Act on the concerns raised by RECs about the taking, storage and use of human tissue.

\section{METHODS}

We analysed letters issued by NHS RECs in England and Wales to applicants following the first meeting at which an application was considered. Letters were sampled from the National Research Ethics Service's (NRES) Research Ethics Database. We aimed to analyse letters about applications involving the use of human tissue, including tissue from living donors and post-mortem tissues, and from children and adults, from both before and after the implementation of the HT Act. The definition of 'tissue samples' included specific mention of 'tissue' but also any reference to the use of human material, e.g. blood, skin biopsies, paraffin blocks and so on.

We aimed to analyse letters in two periods: first, a period when there was still legal uncertainty over storage and use of human tissues for research, and second, a period immediately after the implementation of the HT Act and when practical guidance was available. We sampled 100 letters in 
total; this sample size was chosen for pragmatic reasons. Half of the letters were randomly sampled from a period we call 'Before' the implementation of the Act. This period covers 1 March 2004 (when the database opened) up to and including $31^{\text {st }}$ August 2005 . The Before period covers an era of considerable uncertainty about legal issues relating to research use of human tissue. The Human Tissue Bill was first published in December 2003, but underwent very significant amendments before receiving Royal Assent in November 2004. Though the Act laid out a broad framework, many of the details remained unsettled for some time. The Human Tissue Authority came into being on 1 April 2005, but its statutory functions did not begin until April 2006, when it launched its framework for licensing. Eight detailed Codes of Practice to provide practical guidance were approved by the Department of Health and parliament and were published in July 2006. The Act was implemented for research purposes in September 2006, and licenses for storing human tissue for research purposes were also required from 1 September 2006. The other half of our letters were randomly selected from a period we term 'After', between $1^{\text {st }}$ September 2006 and $22^{\text {nd }}$ December 2006. All letters related to applications where the applicants had indicated (via a tick box on the application form) that their project involved the use of tissue samples.

Letters were included if they communicated a provisional opinion or an unfavourable opinion at first review (Box 1); letters communicating favourable opinions were excluded as they contain no requests for changes, offering little opportunity for analysis. We excluded letters where the final decision was unknown, as well as letters in response to requests for protocol amendments and sitespecific assessments.

\section{Box 1: Decisions RECs may make}

- A 'favourable' opinion means that an application is approved without further revisions; these constitute $\sim 17 \%$ of decisions made by RECs at first consideration of an application.*

- 'Provisional' opinions constitute $\sim 66 \%$ of decisions at first review, and require applicants to make a response addressing issues raised in the letter before a final opinion can be issued. The final opinion may be either favourable or unfavourable.

- An 'unfavourable' opinion ( $8 \%$ of all submissions) at first review amounts to a rejection.

RECs may also decide that applications are 'outside remit'.

Some applications are withdrawn ( $10 \%$ before review and $\sim 2 \%$ after a provisional opinion has been issued).

*Data based on the period October 2005-March 2008 from the NRES website and refer to all applications.

Content analysis and ethnographic content analysis were used to analyse the letters. ${ }^{8}$ The content of letters was coded to a set of categories derived from the 'requirements for a favourable opinion' in the Governance Arrangements for Research Ethics Committees (GAfREC). ${ }^{9}$ An additional grounded set of categories was generated through inspection and comparison of letters used in a previous study, ${ }^{10}$ and modified in response to the new data in this project. Explicit category specifications aided data assignment to analytic categories, which was undertaken using QSR N6. Statistical analysis was not appropriate given the small numbers in our samples, but it was possible to offer simple counts of findings in particular categories and to compare these.

Our project was deemed by NRES not to require research ethics committee review as it was considered to be service evaluation. Letters were fully anonymised before analysis, and where appropriate identifying details have been modified or removed. Quotations are labelled as ' $A$ ' for the 'after HT Act' sample and 'B' for the 'before HT Act' sample. 


\section{RESULTS}

There were 2640 applications for ethical approval to use human tissue in the Before period that received unfavourable/provisional opinions, forming $26 \%$ of the total number of applications meeting our inclusion criteria relating to unfavourable/provisional opinions. The After period included 423 applications for ethical approval to use human tissue that received unfavourable/provisional opinions, forming $40 \%$ of the total applications meeting our decision inclusion criteria in that period. Of the 100 applications in our sample, 48/50 in the Before sample and $45 / 50$ in the After sample received a provisional opinion followed by a favourable opinion, six (1 Before \& 5 After) received an unfavourable opinion at first review and one (1 Before \& 0 After) received a provisional opinion followed by an unfavourable opinion. Applications were to conduct a variety of study types, and involved a mix of new tissue samples, archived tissue samples, tissues collected specifically for research, and 'surplus' tissues (Table 1).

Table 1: Types of studies involving human tissue in applications before and after the HT Act

\begin{tabular}{|l|l|l|l|}
\hline & After HT Act & Total \\
\hline $\begin{array}{l}\text { Application to conduct a Clinical Trial of an Investigational } \\
\text { Medicinal Product (CTIMP) }\end{array}$ & 23 & 18 & 41 \\
\hline Application to conduct a non-CTIMP project & 27 & 32 & 59 \\
\hline New tissue samples only & 33 & 42 & 75 \\
\hline Archived samples only & 5 & 0 & 5 \\
\hline Archived and new tissue samples & 12 & 8 & 20 \\
\hline Tissue specifically collected for research only & 34 & 31 & 65 \\
\hline Surplus tissue only & 7 & 6 & 13 \\
\hline Specifically collected tissue and surplus tissue & 4 & 13 & 17 \\
\hline
\end{tabular}

\section{Ethical issues raised}

Ethical issues raised in REC letters in response to these applications were similar to those found in a previous analysis of REC decision letters across a wide range of study types, ${ }^{10}$ and there was little difference in the nature of issues raised between the Before and After samples (Table 2). Issues relating to informed consent were most frequently raised, consistent with other applications for ethical approval to conduct research. ${ }^{10,11}$ Many (41) letters did not raise concerns specifically relating to human tissue, but $27 / 50$ in the Before sample and $32 / 50$ in the After sample did identify ethical troubles specifically related to tissue collection, storage or use.

Table 2: Issues raised in REC decision letters before and after the HT Act

\begin{tabular}{|l|r|r|r|}
\hline Ethical issues & Before HT Act & After HT Act & Total letters \\
\hline Informed consent process & 42 & 47 & 89 \\
\hline Care and protection of participants & 27 & 27 & 54 \\
\hline Documentation & 27 & 26 & 53 \\
\hline Scientific design and conduct & 21 & 27 & 48 \\
\hline Recruitment of participants & 25 & 22 & 47 \\
\hline Protection of participants' confidentiality & 24 & 22 & 46 \\
\hline Non-GAfREC issues & 9 & 15 & 24 \\
\hline Community considerations & 1 & 5 & 6 \\
\hline
\end{tabular}

\section{Informed consent: general concerns}

Nineteen letters (32\% of the 59 letters specifically mentioning ethical concerns relating to tissue) addressed the adequacy of the proposed consent process for human tissue. Overall the proportion of concerns about informed consent about human tissue was lower in the After sample $(7 / 32,22 \%)$ than the Before sample $(12 / 27,44 \%)$. 
In both the Before and After samples, RECs were concerned about the provision of information to patients and the adequacy of consent, relating to: who would be allowed to conduct research on the tissue; protection of the tissue samples; which countries the tissues would be sent to; and length of storage. RECs were concerned about the need to gain consent specifically for genetic testing, in letters from both before and after the HT Act. Such concerns about consent were more likely to focus on the potential for 'moral' wrongs than direct risks of physical harm.

Whilst parents may accept the concept of research being done using their children's samples, some may feel more strongly about whether it was done locally or samples transferred elsewhere to unknown researchers. (B1551, non-CTIMP, new and stored tissue, BEFORE)

If blood tests are to be used for genetic analysis then this should be described in the information sheet and added to the consent form. (A384, non-CTIMP, new and stored tissue, AFTER)

\section{Concerns about consent for taking tissue}

In both the Before and After samples, RECs commented explicitly on the need for: clarity in information given to patients about whether procedures from which tissue samples would be collected were part of normal care or were being undertaken specifically for research purposes; the need to highlight any risks associated with additional procedures; and the need to obtain separate consent to additional procedures.

You should be explicit in the PIS what procedures are additional to normal care, and what is just another test on an existing sample. (A73, non-CTIMP, new tissue only, AFTER)

The Consent Forms should have a separate clause allowing the participants to consent to having blood samples taken. (B400, non-CTIMP, new tissue only, BEFORE)

Include details of the risks of having the additional biopsies [...]. (A49, CTIMP, new and stored tissue, AFTER)

\section{Concerns about consent for using tissue}

In the Before sample, 10 letters raised concerns relating to consent to the use of tissue, but only one letter raised such concerns in the After sample. There was evidence in these 10 Before letters that RECs wanted to be reassured that researchers were taking appropriate steps to gain full informed consent for any plans to use tissue.

The Chair commented that the Pharmacogenetic Informed Consent Form needed to give specific information to the volunteers and inform them of exactly what the samples were going to be used to research. (B244, CTIMP, new tissue only, BEFORE)

Some of the Before letters reflected uncertainty and lack of clarity on the part of RECs about whether insisting on separate informed consent for the use of tissue was the right thing to do in the context of certain studies, particularly where they involved stored or surplus tissue. However, RECs in the Before period seemed reluctant to approve research to be undertaken without consent, and showed a tendency to err on the side of caution, requiring informed consent even when they seemed unsure if this was the best course of action.

The Committee discussed the protocol at great lengths in particular where there was a real need to formally obtain patient consent for the use of the redundant samples. The current national guidelines were felt to be very unclear and inconsistent regarding the use of such 
tissue. Most members felt that the patients would be surprised at the need to give such consent.[...] The Committee's conclusion was to give a favourable ethical opinion [...] of the research as presented.... (B1684, non-CTIMP, stored tissue only, BEFORE)

Your understanding was that under the new HTA locally organised research procedures could take place without consent. Chairman pointed out that this was not yet law ... Therefore the committee considered it would be safer to ensure that informed consent was obtained.

(B1551, non-CTIMP, new and stored tissue, BEFORE)

In the Before sample, RECs were sometimes willing to consider allowing the use of tissue without consent, especially where consent would be impractical and insisting on consent would obstruct the progress of potentially valuable research, but they also expressed some uneasiness about this.

The researcher states that most of the samples used will be from patients who have given their consent for their tissue samples to be used in any future studies. The committee would like reassurance that consent will be obtained in all cases where it is possible to do so (archival material excepted). (B2252, non-CTIMP, stored tissue only, BEFORE)

Researchers who held banked tissue, possibly obtained without consent... may wish to add it to the bank retrospectively. You felt it would add significant value to the bank if it were possible to include such samples, and considered it impractical to go back to individuals to obtain consent. Before making a decision committee would like to know what percentage of samples were stored without consent. However the concept and principle of informed consent was reinforced. (B1551, non-CTIMP, new and stored tissue, BEFORE)

There were clear indications in the Before sample that RECs were looking to the introduction of the HT Act to provide them with definitive guidance about what was acceptable.

The Committee felt that because of the Human Tissue Act they could offer approval for 2 years, after which time the researcher would need to request an extension to continue, making any modifications required by the Human Tissue Act (B376, non-CTIMP, new tissue only, BEFORE)

In the After sample, only one letter raised concerns about consent to use tissue. In this case, the REC asked for clarification from the attending researcher and seemed comfortable to grant approval for the research to go ahead without consent.

the Committee queried whether consent would have been gained to use all the samples. $<$ Named researcher $>$ explained ....samples pre-2002 may not always have complete documented consent status. <Named researcher> stated that he felt it would be ethical to use this tissue unless specific objections were recorded. The Committee accepted this view. (A215, non-CTIMP, new and stored tissue, AFTER)

\section{Concerns about consent for storing tissue}

Concerns relating to the storage of tissue were raised in 11 letters in the Before sample and six letters in the After sample. In both the Before (7) and After (6) letters, RECs were concerned that participants should be informed about plans for the storage and future use of tissue, and that informed consent should be obtained for this. In the After sample there was some evidence that RECs were more explicit in their requirements about what information should be provided to participants in order for consent to be fully 'informed'. RECs were also more likely to refer to issues 
of anonymisation/identifiability in relation to future use of the tissue in letters after the Act; the HT Act makes anonymisation of tissue a condition for storage and future research without consent.

Is it likely that any prospectively collected pancreatic tissue will remain after completion of this research and will this be stored and used in future projects? If so, this should be made clear in the information sheet and provision for specific consent for this should be made in the consent form. (B839, non-CTIMP, new and stored tissue, BEFORE)

An additional point should be added relating to the blood samples to say what will happen to them and should include ... possible intended use in future for research that cannot yet be specified (and should be clear if further REC approval will be sought); who will have access; level of identifiability (for this study and storage for future studies); provision for destruction etc. (A1, non-CTIMP, new tissue only, AFTER)

You will re-word the consent form to include that future use of samples would be anonymised. (A310, non-CTIMP, new tissue only, AFTER)

In both the Before and After samples, RECs seemed willing to accept consent to generic future use, with the exception of a single letter in the After sample, where the REC expressed concern about the possibility of use of tissue beyond the scope of the proposed study.

Reassure that the samples will only be used for the purpose of this study. (A78, non-CTIMP, new tissue only, AFTER)

The most noticeable contrast between the Before and After letters related to the conditions attached to future use of the tissue. In the Before sample, RECs tended to draw on their own authority as ethical gatekeepers to ensure that conditions relating to the future use of tissue were adhered to.

Patients would need to consent for storage and future use of this sample. Members wish to point out that any future analysis on these samples in research would need the approval of the committee. (B2518, non-CTIMP, new tissue only, BEFORE)

In contrast, in the After sample, there was evidence of RECs drawing on the provisions of the HT Act as a source of authority as to the legal conditions incumbent on storing data for future use, and of increased consistency in their advice about the range of options that researchers could follow for storing and using the tissue in future research.

As you have made a project based application to the Committee, the storage of samples beyond the end of the study for use in future research will need a licence from the Human Tissue Authority. The other alternatives available to you are: Before the end of this project you may make a new project based application to the Committee to conduct research on the remaining samples; The tissue may be deposited in an existing licensed tissue bank...; If none of the above apply, the tissue must be destroyed in an approved manner. (A235, non-CTIMP, new tissue only, AFTER)

\section{DISCUSSION}

Our study looking qualitatively at the content of letters written by Research Ethics Committees to researchers seeking approval to use human tissue for research purposes indicates that the impact of the HT Act 2004 has been primarily to provide clarity and increased certainty about legal and ethical 
issues. The numbers of letters raising concerns specifically about tissue were similar before and after the Act, and there was no noticeable difference in RECs' general concerns about informed consent, including consent to take tissue. However, RECs seemed less inclined to raise concerns about consent for the use of tissue in the After sample. There were also contrasts between the Before and After letters in RECs' approaches to raising concerns and giving advice. In the Before sample there was evidence of a degree of uncertainty governing REC decisions about consent to use and store tissue; RECs drew on their own ethical standards, but were clearly looking to the future for more definitive guidance. In contrast, the letters in the After sample drew on the authority of the Act, demonstrating a more consistent approach, and providing more authoritative advice to researchers.

Our study design does not allow us to analyse the materials submitted to RECs. It is thus difficult to comment on how far the absence of comments on particular issues reflects the REC's perception that all was well with the application, or how far it might reflect a lack of attention by the REC to these issues. We might argue, however, that the changes we have observed are likely to be due to increased clarity and certainty about what is allowed and what is needed to secure a favourable opinion from a REC. The HT Act and the Codes of Practice and other advice from the Human Tissue Authority, as well as training provided by NRES, is likely to have provided enhanced clarity for researchers as well as RECs. The differences in the nature of concerns raised in the After sample compared with the Before sample may at least partly be a result of researchers drawing on these sources of authority and being more likely to propose solutions to ethical troubles related to human tissue that are consistent with REC judgements. It is also possible that researchers no longer choose to apply to conduct research which is likely to be viewed unfavourably by RECs.

By making research without consent legally permissible on approval by a REC, the HT Act may have eased some of the tensions and conflicts for RECs between perceived responsibilities for ensuring appropriate informed consent, and desires to act as responsible stewards for research data, ensuring that potentially valuable research is not obstructed when gaining consent would be impractical. The introduction of the Act means that RECs no longer have to make judgements and decisions about the need for consent by drawing on their own ethical principles, but can draw on legal guidelines which provide consistent and authoritative guidance.

In conclusion, we found no evidence that, in the wake of the HT Act, RECs are more cautious about approving research to use or store tissue without consent. Rather, it seems that the number of concerns raised by RECs about informed consent to use or store tissue in the After sample has reduced, and there is increased transparency in REC decision-making and advice to researchers. Our data suggest that the HT Act has provided clarity and authority to RECs and may indeed facilitate the process of gaining ethical approval for tissue-based research.

\section{ACKNOWLEDGEMENTS}

We thank our colleagues Richard Ashcroft and Neil Sebire for their helpful comments.

\section{COMPETING INTERESTS}

None.

\section{FUNDING}

This project was funded by the National Research Ethics Service (NRES). NRES had no involvement in the study design, in the collection, analysis and interpretation of data, in the writing of this paper, or in the decision to submit the paper for publication. 


\section{Take home messages}

1. The Human Tissue Act has helped to clarify and make consistent certain issues that were previously left to the discretion of the reviewing REC.

2. Informed consent is the issue that trouble RECs the most when they are reviewing applications to take, use or store human tissue for research.

3. RECs are concerned that patients should give explicit consent for the use of the tissue in future projects.

4. RECs appear to be more comfortable to allow tissue to be accessed without consent since the HT Act became law.

\section{References}

\footnotetext{
${ }^{1}$ Human Tissue Act 2004, (2004). Retrieved 4 March, 2009 from http://www.opsi.gov.uk/acts/acts2004/ukpga_20040030 en_1

${ }^{2}$ Mason, K. Laurie, G. (2001). Consent or property? Dealing with the body and its parts in the shadow of Bristol and Alder Hey. Modern Law Review, 64, 710-729.

${ }^{3}$ Harris J. (2002). Law and regulation of retained organs: the ethical issues. Legal Studies (Society of Legal Scholars). 22, 527-549.

${ }^{4}$ NRES, (undated) The Human Tissue Act 2004 - consent, ethical review and licensing http://www.nres.npsa.nhs.uk/applicants/help/faq/the-human-tissue-act-2004/

${ }^{5}$ Human Tissue Authority (2006). Code of Practice - Code 1 , Consent http://www.hta.gov.uk/ db/ documents/2006-07-04 Approved by Parliament - Code of Practice 1 Consent.pdf

${ }^{6}$ Furness, P.N. (2006). The Human Tissue Act: Reassurance for relatives, at a price. BMJ, 333, 512.

${ }^{7}$ McHale, J., Habiba, M., Dixon-Woods, M., Cavers, D., Heney, D, Pritchard-Jones, K. (2007). Consent for childhood cancer tissue banking in the UK: the effect of the Human Tissue Act 2004. Lancet Oncology, 8, 266272.
}

${ }^{8}$ Altheide, D. L. (2004). Ethnographic content analysis. In M. S. Lewis Beck, A. Bryman and T. F. Liao (Eds.), The sage enclycopaedia of social science research methods. Thousand Oaks, Ca: Sage.

${ }^{9}$ Central Office for Research Ethics Committees. (2001). Governance arrangements for research ethics committees (GAfREC). Retrieved 3 March, 2009 from http://www.dh.gov.uk/assetRoot/04/05/86/09/04058609.pdf

${ }^{10}$ Angell, E., Jackson, C. J., Ashcroft, R. E., Bryman, A., Windridge, K., and Dixon-Woods, M. (2007). Is 'inconsistency' in research ethics committee decision-making really a problem? An empirical investigation and reflection. Clinical Ethics, 2, 92-99.

${ }^{11}$ Dixon-Woods, M., Angell, E.L., Tarrant, C., Thomas, A. (2008). What do research ethics committees say about applications to do cancer trials? Lancet Oncology, 9, 700-701. 